\title{
Low birth weight in relation to maternal age and multiple pregnancies at Muhimbili National Hospital
}

\author{
By Adamson, Harold (MD4 - 2006/2007)
}

\begin{abstract}
Objectives: To determine the relationship between Low Birth Weight (LBW), maternal age and multiple pregnancies

Methods: A retrospective cross-sectional study was done where by data were obtained from labor ward register books and computer database of the MNH labour ward and analyzed by using EPI-INFO version 6 computer program.
\end{abstract}

Setting: Muhimbili National Hospital (MNH)

Results: A total of 6931 infants were studied. Prevalence of LBW and multiple births were $26.4 \%$ and $2.9 \%$ respectively. There was no significant association between age of mother with LBW although a significant association between multiple pregnancy and LBW was noted.

Conclusion \& Recommendations: Multiple pregnancy contribute substantially to LBW. There is a need of ensuring proper antenatal care and also highlighting the need both for basic supportive care facilities and improved disease prevention strategies.

\section{INTRODUCTION}

Birth weight is the first weight of the fetus or newborn obtained after birth preferably measured within the first hour of life before significant postnatal weight loss has occurred. Low birth weight is defined as that less than $2,500 \mathrm{~g}$.

A baby's low birth weight is either the result of preterm birth (before 37 completed weeks of gestation) or of restricted fetal (intrauterine) growth. Restricted fetal growth results in small for gestational age babies that are babies born with birth weight below $10^{\text {th }}$ centile for that gestational age. Low birth weight thus defines a heterogeneous group of infants: some are born early, some are born growth restricted and others are born both early and growth restricted. It is generally recognized that being born with low birth weight is a disadvantage for the baby.

Majority of low birth weight babies are born premature. Preterm birth is the main cause of death, morbidity and disability. The shorter the gestation, the smaller the baby and the higher the risk of death, morbidity and disability. It has been shown that the mortality range can vary 100 fold across the spectrum of birth weight and rises continuously with decreasing weight. Low birth weight due to restricted fetal growth has a poor prognosis compared to that due to preterm birth. It affects the person throughout life and is associated with poor growth in childhood and a higher incidence of adult diseases such as type 2 diabetes, hypertension and other cardiovascular diseases. An additional risk for girls is having smaller babies when they become mothers.

Low socio-economic status is the underlying cause of low birth weight. Other causes include maternal malnutrition; maternal diseases like antepartum hemorrhage, anaemia, cervical incompetence; adolescent pregnancies; short birth intervals; intrauterine infections; multiple pregnancy; congenital malformations; placental dysfunction etc. Also it has been documented that there is increased risk of low birth weight among young mothers ( $<20$ years) as compared to mothers above 20 years.

There are a number of problems associated with low birth weight. Symptomatic hypoglycemia, polycythermia, intrauterine hypoxia, birth asphyxia, aspiration in utero and congenital malformations are more associated with small for dates babies. While hyaline membrane disease, apneic attacks, hypothermia, inability to suck and swallow, hyperbilirubinaemia, susceptibility to infections and intraventricular hemorrhage are much more related to preterm babies.

Low birth weight can be prevented by improving socio-economic status and health 
status of the community, improving antenatal care and also by providing proper health education. ${ }^{1}$

Multiple gestations are high risk pregnancies, which may be complicated by pre-maturity, low birth weight infants, preeclampsia, anemia, postpartum hemorrhage, intrauterine growth restriction, neonatal morbidity and high perinatal, neonatal and infant mortality. The rate of multiple gestation pregnancies has grown exponentially over the last few decades and is responsible for the steady increase in the rate of low birth weight infants. As a group, infants of multiple gestation pregnancies have higher mortality and morbidity than singleton pregnancies. The increase in adverse outcomes is related to the increased risk of preterm delivery and low birth weight, and not to the multiple gestation itself. Efforts to reduce the birth rate of low birth weight infants should target multiple gestation pregnancies. ${ }^{2}$

The most significant and common complication of multiple pregnancy is preterm labor resulting in preterm delivery. Perinatal morbidity and mortality are affected by gestational age and weight at delivery as well as by the number of fetuses. Patient education, risk assessment, serial cervical evaluation by manual or transvaginal ultrasound examinations, specialized ante partum clinics will be useful to prevent preterm birth in multiple gestations. $^{3}$

\section{METHODOLOGY}

A descriptive retrospective hospital-based cross sectional study was conducted at neonatal unit of Muhimbili National Hospital, Dar es Salaam Tanzania, where by all babies with low birth weight admitted in January to December 2006 where considered.

Data was collected from the neonatal unit register books and the computer database of the MNH and analyzed using EPI-INFO version 6 computer program.

Permission to conduct the study was sought from $\mathrm{MNH}$ and all data obtained was treated with maximum confidentiality.

\section{RESULTS}

The study population comprised 6931 infant, 63\% (4366) were males. 1832 had LBW of which $58 \%$ ( 1062) were male.

Table 1: Distribution of birth weights

\begin{tabular}{|c|c|c|c|}
\hline $\begin{array}{c}\text { Birth weight } \\
(\mathrm{kg})\end{array}$ & $<2.5$ & $>2.5$ & Total \\
\hline No. $(\%)$ & $1832(26.4)$ & $5099(73.6)$ & $6931(100)$ \\
\hline
\end{tabular}

Total number of newborns delivered at MNH in 2006 was $6931.1832(26.4 \%)$ babies were born with birth weights of less than 2.5 kilograms, 5099 babies which is $73.6 \%$ of all babies born in 2006 at MNH had birth weight above 2.5 kilogram.

Thus the prevalence of low birth weight among babies born at MNH in 2006 was $26.4 \%$.

Table 2: Distribution of singletons and multiple births

\begin{tabular}{|l|l|l|}
\hline Singletons (\%) & Multiple births (\%) & Total (\%) \\
\hline $6725(97.1)$ & $206(2.9)$ & $6931(100)$ \\
\hline
\end{tabular}

The total number of singletons born at MNH in 2006 was 6725 which is $97.1 \%$ of all babies. Number of multiple pregnancies is 206 which are $2.9 \%$ of all babies.

The prevalence of multiple births was $2.9 \%$ 
Table 3: Distribution of Age against Birth weight

\begin{tabular}{|l|r|r|r|}
\cline { 2 - 4 } \multicolumn{1}{c|}{} & \multicolumn{3}{c|}{ Birth weight (kg) } \\
\hline Age (years) & $<2.5$ & \multicolumn{1}{c|}{$>2.5$} & Total \\
\hline $16-20$ & $315(17.2 \%)$ & $917(18.0 \%)$ & $1232(34.3 \%)$ \\
\hline $21-25$ & $655(35.7 \%)$ & $1391(27.3 \%)$ & $2046(47.1 \%)$ \\
\hline $26-30$ & $531(29.0 \%)$ & $1933(37.9 \%)$ & $2464(27.5 \%)$ \\
\hline $31-35$ & $203(11.1 \%)$ & $632(12.4 \%)$ & $835(32.1 \%)$ \\
\hline$>35$ & $128(7 \%)$ & $226(4.4 \%)$ & $354(\%)$ \\
\hline Total & $1832(100 \%)$ & $5099(100 \%)$ & $6931(100 \%)$ \\
\hline
\end{tabular}

There were 1832 LBW babies born at $\mathrm{MNH}$ in 2006,315 babies (17.2\% of LBW babies) were born from mothers of the age between 16- 20 years old, 655 babies (35.7\% of LBW babies) were born from mothers of 21-25 years old, 531 babies (29\% of LBW babies) were born from mothers of 26-30 years of age, 203 babies (11.1\%) from mothers of $31-35$ years old and 128 babies (7\%) from mothers above 35 years of age.

The large numbers of LBW babies were born from mothers of 21-25 years of age.

Table 4: Distribution of singletons and multiple pregnancies

\begin{tabular}{|l|l|l|l|}
\hline Birth weight $(\mathrm{kg})$ & Singletons & $\begin{array}{l}\text { Multiple } \\
\text { pregnancies }\end{array}$ & Total \\
\hline$<2.5$ & $1640(24.4 \%)$ & $192(93.2 \%)$ & 1832 \\
\hline$>2.5$ & $5085(75.6 \%)$ & $14(6.8 \%)$ & 5099 \\
\hline Total & $6725(100 \%)$ & $206(100 \%)$ & 6931 \\
\hline
\end{tabular}

Among 1832 babies born with LBW at MNH in $2006,24.4 \%$ were singletons, $93.2 \%$ were multiple babies.

The large percentage of LBW babies were multiple pregnancies.

\section{DISCUSSION}

In this study, the prevalence of LBW among babies born at MNH in 2006 was found to be $26.4 \%$. This is slightly higher compared to that study done in 1990 at MNH neonatal unit by Manji et al which found the incidence of LBW to be $16 \% .^{5}$ This slight difference can be explained as follows, the study done by Manji et al involves all those neonates admitted in the neonatal unit some of which were not born at MNH but in this study it involved only those born at $\mathrm{MNH}$. Higher levels of LBW have been shown in Bangladesh that is $26.7 \%$ in a study done in July 1989 -june $1990 .^{6}$

Many studies done so far have showed that there is association of LBW and maternal age of less than 20 years and more than 32 years of age. In this study the prevalence of LBW is high in mothers of age between 21 and 25 years. Several reasons can explain this; firstly the number of mothers of less than 20 years old and those of more than 32 years of age who gave birth at $\mathrm{MNH}$ in 2006 was very small when compared to that of mothers of 21 to 25 years of age.

The study also showed that the prevalence of multiple births at MNH in 2006 was 2.9\%. The prevalence of multiple births in Tanzania is not known; in this study the prevalence of LBW in multiple births is higher than in singletons. Higher levels of LBW have been shown also in study done in July 1988 in rural Tanzania. ${ }^{7}$

\section{CONCLUSION}

The prevalence of LBW in babies born in 2006, singletons and multiple births is $24.4 \%$ and $93.7 \%$ respectively. There is no significant association between LBW and maternal age of less than 20 years.

\section{RECOMMENDATIONS}

Efforts should be done by the country through its Ministry of Health to reduce the overall prevalence of LBW. Importance of proper antenatal care should be reemphasized to the community as whole. Pregnant mothers should attend antenatal 
care as regularly as required. Accurate records taking and keeping should be practiced as these are very important; they help us to know where we are coming from and where are we leading in terms of the health status of the country.

\section{REFERENCES}

1. World Health Organization, International statistical classification of diseases and related health problems, $10^{\text {th }}$ revision, World Health Organization, Geneva, 1992.

2. Kilsztajn S, Rossbach A, do Carmo MS, Sugahara GT. Prenatal care, low birth weight and prematurity in Sao Paulo State, Brazil, 2000] Rev Saude Publica. 2003 Jun; 37(3):303-10.

3. Verhoeff $F H$, Brabin BJ, van Buuren $S$, Chimsuku L, Kazembe P, Wit JM, Broadhead RL.An analysis of intrauterine growth retardation in rural Malawi. Eur J Clin Nutr. 2001 Aug; 55(8):682-9.
4. Simiyu DE.Morbidity and mortality of low birth weight infants in the new born unit of Kenyatta National Hospital, Nairobi. East Afr Med J. 2004 Jul; 81(7):36774.

5. Manji KP, Massawe AW, Mgone JM, Birth weight and neonatal outcome at the Muhimbili Medical Centre, Dar es Salaam, Tanzania. East Afr Med J. 1998 Jul; 75(7):382-7.

6. Lao TT, Ho LF. The obstetric implications of teenage pregnancy, Hum Reprod. 1997 Oct;12(10):23035.

7. van Roosmalen J, Multiple pregnancy as a risk factor in rural Tanzania, Trop Geogr Med. 1988 Jul;40(3):196-200.

8. Mazhar SB, Peerzada A, Mahmud G, Maternal and perinatal complications in multiple versus singleton pregnancies: a prospective two years study, J Pak Med Assoc. 2002 Apr;52(4):143-7. 